\title{
Pain-related and performance anxiety and their contribution to pain in music students: a pilot study
}

\section{BACKGROUND}

Pain complaints are common among musicians, whose occupation is highly demanding on both a physical and a psychological level. The purpose of the present study was to better understand the severity of musculoskeletal pain in orchestra musicians by measuring the potential contributions of biological (medical diagnosis), psychosocial (age, gender, instrument, practice and exercising history, and occupational satisfaction), and psychological (pain-related anxiety, performance anxiety, and affect) variables.

\section{PARTICIPANTS AND PROCEDURE}

Data were collected from 59 music students playing in a symphonic orchestra. Univariate analyses were performed to assess differences in biological, psychosocial, and psychological predictors, using the presence or absence of pain as the dependent variable. Regression analyses were performed to develop a model of variance to explain the severity of pain.

\section{RESULTS}

The results revealed lower occupational satisfaction to be associated with the presence of pain. However, a greater proportion of variance $(31 \%)$ in pain severity was explained by pain-related anxiety combined with performance anxiety. Thus, the model that would best explain playing-related pain in musicians would need to focus mainly on psychological variables, namely pain-related and performance anxiety.

\section{CONCLUSIONS}

Further investigation is needed to determine how treatment of musculoskeletal pain in musicians should address these psychological variables.

\section{KEY WORDS}

musculoskeletal pain; pain-related anxiety; performance anxiety; orchestra musicians 


\section{BACKGROUND}

According to the results of a recent study, musculoskeletal problems are more frequent in symphony orchestra musicians than in the general population (Paarup, Baelum, Holm, Manniche, \& Wedderkopp, 2011). Investigating pain problems in musicians, Kenny and Ackermann (2013) reported a 50\% prevalence rate. In a sample of 330 university freshman music students, $79 \%$ reported a history of playing-related pain (Brandfonbrener, 2009). A large-scale survey of 1046 musicians (Wynn Parry, 2004) revealed that while some of these musculoskeletal symptoms may have had a clear-cut pathology (Hoppmann, 2010), the majority of them $(52 \%)$ did not; rather, they were shown to be associated with such symptoms as fatigue and pain. Most importantly, pain experienced by musicians is believed to interfere with artistic performance, as indicated by $87 \%$ of a sample of orchestra musicians (Kaneko, Lianza, \& Dawson, 2005).

The framework for the current study embraces a biopsychosocial conception of pain in musicians. The set of predicting variables includes psychological factors (pain-related anxiety and performance anxiety, as well as positive and negative affect), psychosocial factors (including age, gender, musical practice history, exercising, and occupational satisfaction), and a biological factor (medical diagnosis).

The fear-avoidance model of pain developed by Vlaeyen and Linton (2000) states that catastrophic interpretations related to the occurrence of pain lead to fear and anxiety promoting attentional bias, such as hypervigilance. In turn, anxiety leads to the avoidance of activities perceived to cause pain. This prolonged disengagement, along with catastrophic thinking and hypervigilance, may result in disability and the maintenance of pain. Given that, to our knowledge, no research has been performed to date on the association between pain and pain-related anxiety in musicians, this would seem an interesting avenue for investigation.

Moreover, fear of performing is consistently reported by musicians. Different studies showed prevalence of music performance anxiety to range from $15 \%$ to $59 \%$ (Kenny, Davis, \& Oates, 2004; van Kemenade, van Son, \& van Heesch, 1995; Wesner, Noyes Jr, $\&$ Davis, 1990). The most recent research by Kenny and Ackermann (2013) found pain in this population to be positively linked to music performance anxiety. The current study will verify whether music performance anxiety also has an impact on pain in musicians at an earlier stage of their development.

Finally, in a literature review on the impact of psychological factors on pain, Linton and Shaw (2011) reported associations between negative affect (conceptualized as low mood) and pain. In clinical pain populations, negative affect has been linked to increased pain report (Naylor, Krauthamer, Naud,
Keefe, \& Helzer, 2011) and poor treatment outcomes (Jamison et al., 2013). Also, positive affect has been found to be associated with higher tolerance of physical discomfort (van Laarhoven et al., 2012) and pain reduction (Hood, Pulvers, Carrillo, Merchant, \& Thomas, 2012). Musicians demonstrating low mood are at greater risk of experiencing pain (Leaver, Harris, \& Palmer, 2011), and pain has also been shown to be associated with depression in professional musicians (Kenny \& Ackermann, 2013). It would therefore seem helpful to include a measure of affect in a predicting model of pain in music students: consequently, a measure of both positive affect (PA) and negative affect (NA) was included in the present study.

A recent review by Deeney and O'Sullivan (2009) of the psychosocial factors associated with pain identified occupational satisfaction as a variable potentially associated with musculoskeletal disorders. In a study of psychosocial work environment and orchestral musicians' stress, Holst, Paarup, and Baelum (2012) indicated that this population displays poor job satisfaction as compared to the general working population. They also found low job satisfaction to be related to higher stress symptoms among musicians (Holst et al., 2012). Accordingly, the current study evaluates the impact of occupational satisfaction on pain perception in music students. Finally, the presence or absence of a medical diagnosis explaining musculoskeletal pain related to musical activity was added to the model as a biological predictor of pain.

The general purpose of the present study was to investigate biological, psychosocial, and psychological factors as potential correlates of musculoskeletal pain in advanced music students. The first objective was to determine whether music students who have experienced pain related to their musical activities within the past six months have different biological, psychosocial and psychological characteristics than those who have not experienced pain during that period. The second objective was to investigate relationships between the variables presented above and the severity of pain, conceptualized as the summation of the frequency and duration of pain episodes, intensity of pain, and level of disability reported by musicians. The third objective was to propose a conceptual model that would best predict pain among music students and musicians.

\section{PARTICIPANTS AND PROCEDURE}

\section{SAMPLE}

Participants targeted in the present study were university students majoring in music performance who were also part of a symphonic orchestra. Approval to proceed with this study involving human subjects was obtained from the Board of Ethics of the University of 
Quebec in Montreal. In total, six orchestras were approached. The study's principal investigator contacted the orchestras' musical or administrative directors and explained the project procedure to them. Four of the orchestras gave permission to proceed with recruitment. The first two, the Orchestre de la Francophonie and the Orchestre de l'Académie d'Orford, were part of summer academy music programs in the province of Quebec. Recruitment from these musical ensembles was conducted during summer 2011. The remaining two orchestras, the McGill Orchestra and the University of Manitoba Orchestra, were from major universities in Canada. Participants were recruited from these orchestras during winter 2012.

Data were collected by means of self-report questionnaires. To complete the questionnaires, participants needed to be fluent in English and to provide informed consent. A total of 264 invitations to participate in the study were sent via electronic mail, and 65 answers were received. The total response rate was $24 \%$, with response rates per orchestra of $37 \%$ (25/68), 30\% (22/74), 14\% (10/70), and 15\% (8/52) respectively. Six respondents provided incomplete data and were removed from analyses. In the end, 59 participants were included in the present study. This exceeded the sample size requirement calculated by statistical power analysis performed starting with 11 predictors, an effect size of .20, an $\alpha$ error of .05, and a power of 80 .

\section{MEASURES}

Outcome measure. The outcome variable, severity of pain, is conceptualized as the summation of the frequency and duration, intensity, and disability associated with musculoskeletal pain related to musical activities. This measure was obtained using a validated questionnaire for measuring musician pain, the Musculoskeletal Pain Questionnaire for Musicians (MPQM) (Lamontagne \& Belanger, 2012). The MPQM measures three aspects of self-reported pain: pain-related disability, pain intensity, as well as frequency and duration of pain episodes. The instructions at the beginning of the questionnaire define musculoskeletal pain as follows: Musculoskeletal pain is pain that affects the muscles, ligaments, tendons, bursae, along with the bones (Porter, Kaplan, \& Homeier, 2003). The instructions also specify that the focus of the questions is on musculoskeletal pain perceived to be related to musical activities. The MPQM, as a whole, explains $76.34 \%$ of variance in pain severity, while the individual components accounted for $32.71 \%$ (Disability), 25.42\% (Intensity), and 18.2\% (Frequency and Duration) of variance (Lamontagne \& Belanger, 2012). Overall internal consistency (Cronbach's $\alpha$ ) for the MPQM is .77, while alphas for the three subscales are .89 (Disability), .84 (Intensity), and
.51 (Frequency and Duration). When testing for criterion validity, the MPQM was found to correlate at 65 $(p<.001)$ with the Chronic Pain Grade Questionnaire (Von Korff, Ormel, Keefe, \& Dworkin, 1992).

Biological measure. In addition to the measure of perceived playing-related pain, we collected data on medical diagnoses related to musical activities over the subjects' lifetime, using the following question: Have you ever received a medical diagnosis for musculoskeletal problems related to your playing (e.g., tendinitis, epicondylitis, bursitis)? If yes, please, specify.

Psychosocial measures. Sociodemographic data were collected on age, gender, instrument category, number of years playing the musical instrument, and number of years playing in a university-level orchestra. With regard to instrument practice and physical activity, the following data were also collected: number of hours per week playing the musical instrument (including practice, rehearsal, and concert time), and number of hours per week performing physical activity (sports and exercise).

Occupational satisfaction was measured by a questionnaire derived from the Minnesota Satisfaction Questionnaire-Short Version (MSQ; Weiss, Dawis, England, \& Lofquist, 1977). The original 20-item instrument measures satisfaction related to different aspects of employment such as autonomy, creativity, achievement, and relationships with colleagues. In the version of the questionnaire used for the purposes of the present study, the wording of the instructions and of four of the items was modified. In the instructions, the word "job" was consistently replaced by "occupation as an orchestra musician" as in the present study we were interested in how satisfied students majoring in music were with their occupation as orchestra members. Changes in the items included substitutions such as "musical director" for "boss", and "orchestra" for "company". These new terms were chosen as more relevant to playing in an orchestra as an occupation. Internal reliability for the present sample is adequate, with a Cronbach's $\alpha$ of .88. By way of comparison, Hoyt internal consistency coefficients for the original version of the MSQ ranged from .87 to .92 .

Psychological measures. Positive and negative affect were tested with the Positive and Negative Affect Scale (PANAS) (Watson, Clark, \& Tellegen, 1988), which measures the frequency of positive or negative affect tendencies. Ten adjectives linked to positive affect and ten associated with negative affect were presented to the participant. For the purposes of the current study, subjects were asked to rate, in general, the average frequency of occurrence of each emotion associated with positive and negative affect. This questionnaire was chosen because it covers a wide range of emotions, divided into two relatively independent scales (Crawford \& Henry, 2004): the positive affect (PA) and the negative affect (NA) scales. The test is reliable, with a Cronbach's $\alpha$ of .89 for the PA scale, and of .85 for the
Psychological characteristics and pain in musicians 
NA scale. Validity of the two subscales has also been demonstrated: PA and NA correlate with measures of depression and anxiety (Crawford \& Henry, 2004).

Musician performance anxiety was assessed with the Performance Anxiety Questionnaire (PAQ; Cox $\&$ Kenardy, 1993). The original version measures both cognitive anxiety (10 items) and physiological anxiety (10 items) related to musical performance in three different contexts (solo performance, chamber music performance and orchestral performance). In the present study, only the orchestral performance context was included, with participants rating the frequency of their cognitive and physiological symptoms of anxiety only in orchestral contexts. For the current sample, the PAQ had an internal consistency of $\alpha=.90$ and correlated at $r=.60, p<.001$ with the NA scale.

Pain-related anxiety was measured with the Pain Anxiety Symptom Scale-Short Version (PASS-20) (McCracken \& Dhingra, 2002). This questionnaire is based on the fear-avoidance model of pain (Vlaeyen \& Linton, 2000), as discussed earlier. The PASS-20 by McCracken and Dhingra was selected because it captures the essential components of the pain-related anxiety construct, namely pain-related beliefs, behaviors, emotions and symptoms. This questionnaire has adequate internal reliability, with a Cronbach's $\alpha$ of .81 (McCracken \& Dhingra, 2002). It correlates significantly with measures of pain, depression, physical and psychosocial disability (McCracken \& Dhingra, 2002).

\section{DATA ANALYSIS}

In the initial phase of analysis, the presence or absence of playing-related pain within the past six months was used as the outcome measure. Information on pain was obtained through the first question of the MPQM: In the past six months, how frequently did you experience pain? Pain was defined in the instructions as musculoskeletal pain related to musical activities. Those who answered Never to this question were placed in the group "Absence of pain within the past six months". First, $t$-tests were performed to identify any group differences in terms of psychosocial variables (age, number of years playing the musical instrument, number of years playing in the orchestra, number of hours spent weekly playing the instrument or exercising, and occupational satisfaction) and psychological characteristics (pain-related anxiety, performance anxiety, and positive and negative affect). Fisher's exact test was used for the categorical variables to measure any differences in gender and instrument category frequencies between the group that had experienced pain and the absence-of-pain group.

In the second phase of analysis, the total score of the MPQM was used as the outcome variable. The total MPQM score was preferred over the scores for the different MPQM subscales as the latter were too strongly correlated to allow for independent analyses. Bivariate correlations were calculated to investigate relationships between biological, psychosocial and psychological variables on one hand, and pain on the other. Finally, regression analysis was used to propose an explained variance model for musculoskeletal pain, with all relevant characteristics entered as predictors.

\section{RESULTS}

\section{BIOLOGICAL, PSYCHOSOCIAL AND PSYCHOLOGICAL CHARACTERISTICS}

Twenty-three males (39\%) and 36 females (61\%) took part in the study. The number of participants falling into different instruments categories were as follows: 40 string players (68\%), 10 wind players $(17 \%)$ and 9 brass players $(15 \%)$.

Forty-nine subjects (83\%) reported some level of pain related to musical activities during the past six months, whereas $10(17 \%)$ reported the absence of pain during the same period. Of the musicians who reported playing-related pain, $15(31 \%)$ had received a medical diagnosis explaining the pain symptom, while 34 (69\%) had not. Twenty-five music students (51\%) who reported pain had sought treatment from a health professional.

Table 1 shows psychosocial and psychological characteristics for the total sample, as well as for both the group with pain and the absence-of-pain group. Of the possible factors influencing the presence of pain, only occupational satisfaction was found to be associated with it. The group reporting the presence of pain in the past six months showed lower occupational satisfaction than the absence-of-pain group $(t=2.40, p=.020)$.

\section{BIVARIATE CORRELATIONS}

Bivariate analyses were performed for individuals $(n=49)$ who reported playing-related pain during the previous six months, using pain as measured by the MPQM (Lamontagne \& Belanger, 2012) as the outcome variable. None of the psychosocial variables were associated with pain severity: gender $(t=1.63$, n.s.); instrument category $(F=0.11$, n.s.); age $(r=-.05$, n.s.); number of years playing the musical instrument $(r=-.12$, n.s.); number of years playing within the orchestra $(r=-.05$, n.s.); number of hours exercising $(r=-.09$, n.s. $)$; and occupational satisfaction $(r=-.25$, n.s.). Analysis revealed that medical diagnoses were reported equally by males and females $\left(\chi^{2}=.61\right.$, n.s.). However, the presence or absence of a medical diagnosis did not explain the severity of pain $(t=1.78$, n.s.). Interestingly, some of the psychological variables were associated with pain. Performance anx- 
Table 1

Psychosocial and psychological characteristics

\begin{tabular}{|c|c|c|c|c|c|c|c|}
\hline \multirow[t]{2}{*}{ Characteristics } & \multirow[t]{2}{*}{$\begin{array}{l}\text { Theoretical } \\
\text { range }\end{array}$} & \multicolumn{2}{|c|}{$\begin{array}{c}\text { Total sample } \\
\quad(n=59)\end{array}$} & \multicolumn{2}{|c|}{$\begin{array}{l}\text { Presence of pain } \\
\quad(n=49)\end{array}$} & \multicolumn{2}{|c|}{$\begin{array}{l}\text { Absence of pain } \\
\quad(n=10)\end{array}$} \\
\hline & & $M$ & $S D$ & $M$ & $S D$ & $M$ & $S D$ \\
\hline \multicolumn{8}{|l|}{ Psychosocial } \\
\hline Age & & 22 & 3 & 22 & 3 & 22 & 4 \\
\hline Years playing instrument & & 13 & 4 & 13 & 4 & 14 & 4 \\
\hline $\begin{array}{l}\text { Years playing in a university } \\
\text { level orchestra }\end{array}$ & & 5 & 3 & 5 & 3 & 5 & 3 \\
\hline $\begin{array}{l}\text { Hours/week playing instru- } \\
\text { ment }\end{array}$ & & 29 & 10 & 29 & 10 & 31 & 11 \\
\hline $\begin{array}{l}\text { Hours/week performing } \\
\text { physical activity }\end{array}$ & & 5 & 3 & 5 & 3 & 5 & 3 \\
\hline Occupational satisfaction & {$[20,100]$} & 66 & 11 & 64 & 10 & 73 & 13 \\
\hline \multicolumn{8}{|l|}{ Psychological } \\
\hline Pain-related anxiety & {$[0,100]$} & 33 & 16 & 34 & 16 & 27 & 14 \\
\hline Performance anxiety & {$[20,100]$} & 55 & 15 & 56 & 15 & 48 & 13 \\
\hline Positive affect & {$[10,50]$} & 35 & 7 & 34 & 18 & 38 & 17 \\
\hline Negative affect & {$[10,50]$} & 24 & 7 & 24 & 7 & 20 & 5 \\
\hline
\end{tabular}

iety was positively correlated with severity of pain $(r=.36, p=.010)$, as was pain-related anxiety $(r=.50$, $p<.001)$. Table 2 illustrates bivariate correlations between all psychological variables and the outcome measure.

\section{REGRESSION ANALYSES}

Regression analysis was used to test the model for predicting variation in pain severity. All psychological variables that were previously correlated with the outcome variable were entered simultaneously into the equation. Table 3 presents the results of the regression analysis for performance anxiety and pain-related anxiety as predictors of the level of pain. Performance anxiety and pain-related anxiety were found to explain $31 \%$ of variance in pain severity $\left(R^{2}=31 \%\right)$. This relationship was significant: $F(2,48)=10.38, p<.001$. Performance anxiety explained $5.8 \%$ of total variance, and pain-related anxiety explained $17.6 \%$. The remaining $7.6 \%$ of variance explained was attributable to common variance of performance and pain-related anxiety. Both the effects of performance anxiety and pain-related anxiety were significant: $t(48)=1.98$, $p=.054$; and $t(48)=3.46, p=.001$ respectively.

\section{DISCUSSION}

This study provided interesting results regarding the contribution of biological, psychosocial and psycho-
Psychological characteristics and pain in musicians

Table 2

Correlation matrix: relationships between psychological variables and pain

\begin{tabular}{lccccc}
\hline & $\begin{array}{c}\text { Perceived } \\
\text { pain } \\
(\text { MPQM) }\end{array}$ & $\begin{array}{c}\text { Pain-related } \\
\text { anxiety } \\
\text { (PASS) }\end{array}$ & $\begin{array}{c}\text { Performance } \\
\text { anxiety } \\
\text { (PAQ) }\end{array}$ & $\begin{array}{c}\text { Positive } \\
\text { affect } \\
(\mathrm{PA})\end{array}$ & $\begin{array}{c}\text { Negative } \\
\text { affect } \\
(\mathrm{NA})\end{array}$ \\
\hline Perceived pain (MPQM) & - & & & \\
Pain-related anxiety (PASS) & $.50^{* *}$ & - & - & - \\
Performance anxiety (PAQ) & $.36^{*}$ & .26 & $-.31^{*}$ & $-.31^{*}$ \\
Positive affect (PA) & -.18 & -.24 & $.60^{* *}$ & - \\
Negative affect (NA) & .18 & $.38^{* *}$ & &
\end{tabular}


Table 3

Regression table: predictors of pain

\begin{tabular}{lcccc}
\hline Variable & \multicolumn{4}{c}{ Severity of pain } \\
\cline { 2 - 5 } & $B$ & $S E B$ & $\beta$ & $95 \% \mathrm{Cl}$ \\
\hline Constant & 3.27 & 9.53 & {$[-15.91,22.45]$} \\
Pain-related anxiety & $.52^{* *}$ & .15 & .44 & {$[0.22,0.82]$} \\
Performance anxiety & $.32^{*}$ & .16 & .25 & {$[-0.01,0.65]$} \\
$R^{2}$ & & & .31 \\
$F$ & & & $10.38^{* * *}$ \\
$R^{2}$ adj & & & .28 \\
\hline
\end{tabular}

Note. ${ }^{*} p=.050,{ }^{* *} p<.010,{ }^{* *} p<.001, \mathrm{Cl}-$ confidence interval

logical factors to the presence and absence of playing-related pain, as well as to the severity of pain reported by orchestra musicians. A significant number of musicians (83\%) acknowledged the presence of pain within the six months prior to the study. This percentage is similar to those reported elsewhere (Kaufman-Cohen \& Ratzon, 2011; Leaver et al., 2011). These similarities in prevalence rates seem to exist despite the difference in employment status: music students (current study) versus professional musicians (Kaufman-Cohen \& Ratzon, 2011; Leaver et al., 2011). The prevalence rate also seems to be independent of age, as the professional musicians (Kaufman-Cohen \& Ratzon, 2011) were significantly older than the students in the present study $(t=12.44, p<.001)$. This observation raises some important questions regarding the development and evolution of musculoskeletal disorders in musicians: First, when do they appear? More specifically, in what context do they tend to appear? Indeed, components of musical activity such as practice strategies and frequency of public appearances may be influenced by the environment (studies versus employment), and these may impact the onset and maintenance of pain. Second, further investigation is also needed to address the psychological mechanisms that may explain the chronicity of musculoskeletal pain.

In the current study, no difference was found between men and women, either when comparing the groups with and without pain, or when examining the severity of perceived pain. However, many other studies have shown an association between gender and pain in musicians, with females consistently being more affected than males (Davies \& Mangion, 2002; Roach, Martinez, \& Anderson, 1994; Zaza, 1992; Zaza \& Farewell, 1997; Zetterberg, Backlund, Karlsson, \& Werner, 1998). In fact, some authors have suggested that the female body may be more susceptible to developing pain, providing a gender-based physiological explanation for pain (Roach et al., 1994). In the current study, there is no evidence that severity of pain is associated with a different gender-related physical condition, and our results show no gender differences concerning the presence or absence of a medical diagnosis.

The current study revealed that musicians experiencing pain tend to experience lower occupational satisfaction than musicians who are free of pain. It remains to be determined whether this association holds for lower occupational satisfaction as an antecedent or consequent to pain, or both. Musicians experiencing lower occupational satisfaction may develop attentional biases toward negative events, such as pain, within the occupational setting. Also, the occurrence of pain within the context of musical activity may trigger negative feelings toward the occupation, which may in turn be considered more generally dissatisfying. On the other hand, experiencing the occupational setting as pleasurable may diminish pain sensitivity. Indeed, research has found that high levels of pleasantness experienced within a situation can modulate pain reports (Rhudy, Bartley, \& Williams, 2010). Therefore, musicians who experience greater pleasure in being fully engrossed in music-making may be protected from developing pain. A possible topic for future research might be the impact of pleasantness or unpleasantness during the musical performance experience on the pain reported by the musicians.

With regard to the severity of pain, pain-related and performance anxiety were found to affect musicians' reports. This means that, as a general tendency, the more anxious musicians were, the more severe was the pain they reported. As this is a correlational study, we still do not know the direction of effects. Further study is needed to address the question of which of the two conditions, pain or anxiety, comes first, impacting the second; this could be examined by using a longitudinal design, a qualitative design, or both.

The fear-avoidance model states that there is always an initial trigger (pain occurrence) that leads to the development of catastrophic interpretations, resulting in anxiety toward pain (Vlaeyen \& Linton, 
2000). However, not every individual experiencing pain will develop anxiety. A recent publication shows that pain-related anxiety is associated with the character trait of harm avoidance - fatigability (Knaster, Estlander, Karlsson, Kaprio, \& Kalso, 2012). Future investigation should continue in the same direction, attempting to define the characteristics of the individual (personality traits, coping strategies, etc.) and the characteristics of the pain situation (traumatic pain, chronicity of pain, localisation of pain, etc.) that promote the development of pain-related anxiety.

In the present study, performance anxiety was within a similar range for both groups (presence and absence of pain). However, performance anxiety seemed to be associated with greater severity of pain. It remains to be clarified whether severity of pain is a precursor of greater performance anxiety, or the opposite, whether higher performance anxiety engenders greater pain severity. Both hypotheses deserve to be tested. With respect to the first one, knowing the burden of pain in musicians, it is probable that pain exacerbates pre-existing anxiety. Indeed, pain impacts musicians' lives on numerous levels: in a study on symphony musicians, $40 \%$ of the musicians affected by pain had to stop playing at least once, and $37 \%$ had to significantly reduce the duration of their daily practice (Kaneko et al., 2005). From these data, we can speculate that pain, and its consequences for musical performance, may contribute to intensifying performance anxiety. A second hypothesis that should be tested is that performance anxiety triggers pain. A study of pianists revealed that performance anxiety is associated with increased muscular contractions (Yoshie, Kudo, Murakoshi, \& Ohtsuki, 2009). It therefore seems reasonable to believe that muscular tension associated with performance anxiety may aggravate pain problems. Regarding the impact of pain and performance anxiety on music students in particular, we must take into consideration the highly competitive world within which music majors evolve. Their professional careers are greatly dependent on how well they perform and progress during their musical studies. Therefore, any threat to their performance, such as pain, may trigger anxiety, which may in turn heighten the pain. This circle may continue indefinitely, possibly leading to chronic pain and long-term performance anxiety issues. Our own research group is currently conducting a qualitative study of the relation between pain and anxiety in musicians (Lamontagne, Bélanger, Courchesne, \& Gilbert, unpublished manuscript). Preliminary analysis of the data collected through interviews with musicians shows that musicians have high perfectionist expectations of themselves, which are reinforced by the perceived performance demands of other elements within the musical sphere (other orchestra members, musical directors, the public, etc.). In turn, both the pursuit of perfection and the failure to achieve it seem to be related to self-esteem issues that may translate into performance anxiety. Other researchers have explored individual characteristics that may explain the pursuit of excellence by musicians, and their results show perfectionism to be related to both motivation and distress (Stoeber \& Eismann, 2007). Further studies should include measures targeting both music students' beliefs regarding their need for achievement, and the latter's relation to environmental pressures and ultimately to pain. It might also be helpful for additional investigation of correlates of pain in musicians to consider the relation between pain and distress.

In the current study, positive and negative affect were not significantly related to the severity of pain. We believe that the absence of an association between affect and severity of pain could be attributable in part to the study's relatively small sample size. A recent publication by Crombez, Viane, Eccleston, Devulder and Goubert (2012) shows that together pain intensity, high negative affect, and low positive affect explain $32 \%$ of variance in fearful thinking. Further research should be done to investigate the potential influence of positive and negative affect on pain with a larger sample of musicians.

In summary, the principal findings of the present study are that pain-related and performance anxiety explains an important part of the variance in pain severity and that the psychological model proposed to explain the severity of playing-related pain is gender-neutral. Pain-related anxiety and performance anxiety each have a distinct impact on the severity of pain reported: despite the anxiety common to both variables, it would seem that their effects do not overlap. Overall, holding beliefs that pain is harmful, engaging in avoidant behaviors toward pain, feeling threatened by pain, and showing exacerbated responses to pain may all contribute to musicians experiencing greater severity of pain. This is consistent with the fear-avoidance model of musculoskeletal pain (Vlaeyen \& Linton, 2000). While the consequences of pain experienced by musicians may not be life-threatening, they can be seriously career-threatening (disability, sick leave, career interruptions and terminations, unemployment, etc.) (Zaza, Charles, \& Muszynski, 1998). One might hypothesize that these consequences may be so disastrous to a musician's life that pain is intensely feared; as a result, musicians become hypervigilant of pain and engage in behavioral, emotional, cognitive and physiological responses to pain that result in increased pain and fear. It must also be noted that musicians may still have to perform despite their fear of pain, due to the underlying premise that the show must go on. This obligation to perform may therefore lead to performance anxiety. It may be difficult for musicians to perform on stage, knowing they are not at their best. Future research with musicians might be conducted using diaries as a complement to other measures to
Psychological characteristics and pain in musicians 
delineate the complex ways in which pain-related and performance anxiety may interact, and their relation to pain.

Despite its strengths, this study also presents some weaknesses that limit the interpretation of results. First, this study had a cross-sectional design that did not allow for investigation of the precursors of pain. It is therefore impossible to state whether the psychological variables that predicted the presence or absence of pain or the severity of reported pain preceded or followed the onset of pain. Second, the present study poses certain limits regarding statistical analysis: due to the small sample size and the exploratory nature of the current investigation, we were unable to apply a Bonferroni correction to the tests that were performed. Next, the participation rate, although comparable to that of other studies with musicians (Wu, 2007), was relatively low. Participation biases may have occurred in both directions: some musicians with musculoskeletal problems may have felt threatened by the prospect of taking part in a study on pain, as pain is often perceived as a weakness in musicians (Zaza et al., 1998); or, on the contrary, musicians with pain may have been overrepresented in this sample, as their wish to understand pain may have motivated them to enter the study. Also, as both the primary outcome and all the psychosocial and psychological measures were self-reported, there may have been recall errors, as well as exaggeration or minimization of the elements reported. For example, questions about performance anxiety may have been answered long after an actual performance. Perceived anxiety may therefore have been reported at a lower level than that experienced during the actual performance. Moreover, the biological measure (medical diagnosis) was also recalled by the musicians. In the future, it would be helpful to have physical examinations and imaging as biological measures. Finally, the study was conducted with university music students playing in a symphonic orchestra. This group's experiences and attitudes toward pain and anxiety might not be representative of those of other groups of musicians (professionals or freelancers). However, since university music students are often already engaged in their career, performing both as freelancers and professionals while pursuing their studies, this sample may be considered a fair estimate of other orchestra member populations.

Findings from the present study open the door to a discussion of prophylactic pain treatments focusing on performance anxiety and pain-related anxiety. Treatments that target the body, such as yoga, the Alexander technique, and intensive muscular training, have already been reviewed (Ackermann, Adams, \& Marshall, 2002; Hollinghurst et al., 2008; Khalsa, Shorter, Cope, Wyshak, \& Sklar, 2009). These approaches to pain have in common the idea that good posture and muscular support protect the body from pain when performing tasks that are physically demanding. Although some of these techniques also promote psychological well-being, the emphasis of these postural strategies is on developing awareness of physiological mechanisms.

A complement to these techniques may lie in preventive treatments that encourage awareness of psychological characteristics, such as pain-related and performance anxiety, that seem to be related to problems of pain in musicians. Bailey, Carleton, Vlaeyen and Asmundson (2010) reviewed current cognitive-behavioural treatments for pain-related anxiety in chronic pain patients. The four protocols included in the review were graded in vivo exposure, graded activity, Acceptance and Commitment Therapy (ACT) and mixed cognitive-behavioural protocols (including psychoeducation and problem solving). The authors concluded that graded in vivo exposure and ACT result in the best outcomes for controlling pain-related anxiety. Recently, graded exposure in vivo treatment was used with a sample of eight patients with high pain-related fear, including one musician (de Jong, Vlaeyen, van Eijsden, Loo, \& Onghena, 2012). The treatment resulted in clinically meaningful changes in reducing pain-related fear and disability for the sample (de Jong et al., 2012). The experimental application of this type of treatment with a sample of musicians would constitute another avenue for future research.

A number of attempts have been made to evaluate treatments for performance anxiety in musicians (Clark \& Agras, 1991; Kendrick, Craig, Lawson, \& Davidson, 1982; Sweeney \& Horan, 1982). Cognitive-behavioral treatments have shown success in reducing anxiety in this population (Clark \& Agras, 1991; Kendrick et al., 1982). Cue-controlled relaxation and cognitive restructuring have also been associated with diminished anxiety in musicians (Sweeney \& Horan, 1982). However, none of the treatments have been tested specifically on performance anxiety in relation to pain.

Based on the findings from the present study, pain-related anxiety and performance anxiety seem to make both common and distinct contributions to pain in musicians. It could therefore be of interest both to test the effect of existing treatments that target these psychological variables independently, and to elaborate a new treatment program incorporating elements of in vivo exposure and targeting cognitive and affective components of performance and pain-related anxiety simultaneously. It would then be useful to investigate and compare the efficacy of such treatments in reducing playing-related pain in musicians.

\section{RefERENCES}

Ackermann, B. J., Adams, R., \& Marshall, E. (2002). Strenght of endurance training for undergraduate 
music majors at a university. Medical Problems of Performing Artists, 17, 33-41.

Bailey, K. M., Carleton, R. N., Vlaeyen, J. W. S., \& Asmundson, G. J. G. (2010). Treatments addressing pain-related fear and anxiety in patients with chronic musculoskeletal pain: A preliminary review. Cognitive Behaviour Therapy, 39, 46-63. DOI: 10.1080/16506070902980711

Brandfonbrener, A. (2009). History of playing-related pain in 330 university freshman music students. Medical Problems of Performing Artists, 24, 30-36.

Clark, D. B., \& Agras, W. S. (1991). The assessment and treatment of performance anxiety in musicians. The American Journal of Psychiatry, 148, 598-605.

Cox, W. J., \& Kenardy, J. (1993). Performance anxiety, social phobia, and setting effects in instrumental music students. Journal of Anxiety Disorders, 7, 49-60.

Crawford, J. R., \& Henry, J. D. (2004). The positive and negative affect schedule (PANAS): construct validity, measurement properties and normative data in a large non-clinical sample. British Journal of Clinical Psychology, 43, 245-265. DOI: 10.1348/0144665031752934

Crombez, G., Viane, I., Eccleston, C., Devulder, J., \& Goubert, L. (2012). Attention to pain and fear of pain in patients with chronic pain. Journal of Behavioral Medicine, 36, 371-378. DOI: 10.1007/ s10865-012-9433-1

Davies, J., \& Mangion, S. (2002). Predictors of pain and other musculoskeletal symptoms among professional instrumental musicians: elucidating specific effects. Medical Problems of Performing Artists, 17, 155-168.

de Jong, J. R., Vlaeyen, J.W. S., van Eijsden, M., Loo, C., \& Onghena, P. (2012). Reduction of pain-related fear and increased function and participation in work-related upper extremity pain (WRUEP): Effects of exposure in vivo. Pain, 153, 2109-2118. DOI: http://dx.doi.org/10.1016/j.pain.2012.07.001

Deeney, C., \& O’Sullivan, L. (2009). Work related psychosocial risks and musculoskeletal disorders: Potential risk factors, causation and evaluation methods. Work: A Journal of Prevention, Assessment and Rehabilitation, 34, 239-248. DOI: 10.3233/ wor-2009-0921

Hollinghurst, S., Sharp, D., Ballard, K., Barnett, J., Beattie, A., Evans, M., Lewith, G., Middleton, K., Oxford, F., Webley, F., \& Little, P. (2008). Randomised controlled trial of Alexander technique lessons, exercise, and massage (ATEAM) for chronic and recurrent back pain: economic evaluation. British Medical Journal, 337, a2656. DOI: 10.1136/bmj.a2656

Holst, G., Paarup, H., \& Baelum, J. (2012). A cross-sectional study of psychosocial work environment and stress in the Danish symphony orchestras. International Archives of Occupational and Environ- mental Health, 85, 639-649. DOI: 10.1007/s00420011-0710-z

Hood, A., Pulvers, K., Carrillo, J., Merchant, G., \& Thomas, M. D. (2012). Positive traits linked to less pain through lower pain catastrophizing. Personality and Individual Differences, 52, 401-405. DOI: http://dx.doi.org/10.1016/j.paid.2011.10.040

Hoppmann, R. A. (2010). Musculoskeletal problems of intrumental musicians. In: R. T. Sataloff, A. G. Brandfonbrener, \& R. J. Lederman (eds.), Performing Arts Medicine ( $3^{\text {rd }}$ ed.). Narberth, PA: Science \& Medicine.

Jamison, R. N., Edwards, R. R., Liu, X., Ross, E. L., Michna, E., Warnick, M., \& Wasan, A. D. (2013). Relationship of negative affect and outcome of an opioid therapy trial among low back pain patients. Pain Practice, 13, 173-181. DOI: 10.1111/j.15332500.2012.00575.x

Kaneko, Y., Lianza, S., \& Dawson, W. J. (2005). Pain as an incapacitating factor in symphony orchestra musicians in Sao Paulo, Brazil. Medical Problems of Performing Artists, 20, 168-174.

Kaufman-Cohen, Y., \& Ratzon, N. Z. (2011). Correlation between risk factors and musculoskeletal disorders among classical musicians. Occupational Medicine, 61, 90-95. DOI: 10.1093/occmed/kqq196

Kendrick, M. J., Craig, K. D., Lawson, D. M., \& Davidson, P. O. (1982). Cognitive and behavioral therapy for musical-performance anxiety. Journal of Consulting and Clinical Psychology, 50, 353-362. DOI: 10.1037/0022-006x.50.3.353

Kenny, D., \& Ackermann, B. (2013). Performance-related musculoskeletal pain, depression and music performance anxiety in professional orchestral musicians: A population study. Psychology of $\mathrm{Mu}$ sic. DOI: $10.1177 / 0305735613493953$

Kenny, D. T., Davis, P., \& Oates, J. (2004). Music performance anxiety and occupational stress amongst opera chorus artists and their relationship with state and trait anxiety and perfectionism. Journal of Anxiety Disorders, 18, 757-777. DOI: 10.1016/j.janxdis.2003.09.004

Khalsa, S., Shorter, S., Cope, S., Wyshak, G., \& Sklar, E. (2009). Yoga Ameliorates Performance Anxiety and Mood Disturbance in Young Professional Musicians. Applied Psychophysiology and Biofeedback, 34, 279-289. DOI: 10.1007/s10484-009-9103-4

Knaster, P., Estlander, A.-M., Karlsson, H., Kaprio, J., \& Kalso, E. (2012). Temperament Traits and Chronic Pain: The Association of Harm Avoidance and Pain-Related Anxiety. PLoS One, 7, 1-7. DOI: 10.1371/journal.pone.0045672

Lamontagne, V., \& Belanger, C. (2012). Development and validation of a questionnaire on musculoskeletal pain in musicians. Medical Problems of Performing Artists, 27, 37-42.

Lamontagne, V., Bélanger, C., Courchesne, C. \& Gilbert, S. (unpublished manuscript). Douleur
Psychological characteristics and pain in musicians 
et souffrance chez le musicien d'orchestre: nouvelle conceptualisation autour de l'image de soi.

Leaver, R., Harris, E. C., \& Palmer, K. T. (2011). Musculoskeletal pain in elite professional musicians from British symphony orchestras. Occupational Medicine, 61, 549-555. DOI: 10.1093/occmed/ kqr129

Linton, S. J., \& Shaw, W. S. (2011). Impact of psychological factors in the experience of pain. Physical Therapy, 91, 700-711. DOI: 10.2522/ptj.20100330

Valérie Lamontagne, Claude Bélanger

McCracken, L. M., \& Dhingra, L. (2002). A short version of the Pain Anxiety Symptoms Scale (PASS20): preliminary development and validity. Pain Research Management, 7, 45-50.

Naylor, M. R., Krauthamer, G. M., Naud, S., Keefe, F. J., \& Helzer, J. E. (2011). Predictive relationships between chronic pain and negative emotions: a 4-month daily process study using Therapeutic Interactive Voice Response (TIVR). Comprehensive Psychiatry, 52, 731-736. DOI: http://dx.doi. org/10.1016/j.comppsych.2010.11.008

Paarup, H., Baelum, J., Holm, J., Manniche, C., \& Wedderkopp, N. (2011). Prevalence and consequences of musculoskeletal symptoms in symphony orchestra musicians vary by gender: a cross-sectional study. BMC Musculoskeletal Disorders, 12, 223-237.

Porter, R. S., Kaplan, J. L., \& Homeier, B. P. (eds.). (2003). The Merck Manual Home Health Handbook ( $2^{\text {nd }}$ ed.). Whitehouse Station, NJ: Merck research laboratories.

Rhudy, J. L., Bartley, E. J., \& Williams, A. E. (2010). Habituation, sensitization, and emotional valence modulation of pain responses. Pain, 148, 320-327. DOI: 10.1016/j.pain.2009.11.018

Roach, K. E., Martinez, M. A., \& Anderson, N. (1994). Musculoskeletal pain in student instrumentalists: a comparison with the general student population. Medical Problems of Performing Artists, 9, 125-130.

Stoeber, J., \& Eismann, U. (2007). Perfectionism in young musicians: relations with effort, motivation, achievement and distress. Personality and Individual Differences, 43, 2182-2192. DOI: 10.1016/j. paid.2007.06.036

Sweeney, G. A., \& Horan, J. J. (1982). Separate and combined effects of cue-controlled relaxation and cognitive restructuring in the treatment of musical performance anxiety. Journal of Counseling Psychology, 29, 486-497. DOI: 10.1037/00220167.29.5.486

van Kemenade, J. F. L. M., van Son, M. J. M., \& van Heesch, N. C. A. (1995). Performance anxiety among professional musicians in symphonic orchestras: A self-report study. Psychological Reports, 77, 555-562.

van Laarhoven, A. I. M., Walker, A. L., Wilder-Smith, O. H., Kroeze, S., van Riel, P. L. C. M., van de Kerk- hof, P. C. M., Kraaimaat, F.W., \& Evers, A. W. M. (2012). Role of induced negative and positive emotions in sensitivity to itch and pain in women. British Journal of Dermatology, 167, 262-269. DOI: 10.1111/j.1365-2133.2012.10933.x

Vlaeyen, J. W. S., \& Linton, S. J. (2000). Fear-avoidance and its consequences in chronic musculoskeletal pain: a state of the art. Pain, 85, 317-332.

Von Korff, M., Ormel, J., Keefe, F. J., \& Dworkin, S. F. (1992). Grading the severity of chronic pain. Pain, 50, 133-149. DOI: 10.1016/0304-3959(92)90154-4

Watson, D., Clark, L. A., \& Tellegen, A. (1988). Development and validation of brief measures of positive and negative affect: The PANAS scales. Journal of Personality and Social Psychology, 54, 1063-1070.

Weiss, H. M., Dawis, R. V., England, G. W., \& Lofquist, L. H. (1977). Manual for the Minnesota Satisfaction Questionnaire.

Wesner, R. B., Noyes Jr, R., \& Davis, T. L. (1990). The occurence of performance anxiety among musicians. Journal of Affective Disorders, 18, 177-185. DOI: http://dx.doi.org/10.1016/0165-0327(90)90034-6

$\mathrm{Wu}$, S. J. (2007). Occupational risk factors for musculoskeletal disorders in musicians: a systematic review. Medical Problems of Performing Artists, 22, 43-51.

Wynn Parry, C. B. (2004). Managing the physical demands of musical performance. In: A. Williamon (ed.), Musical excellence: Strategies and techniques to enhance performance (pp. 41-60). London: Oxford University Press.

Yoshie, M., Kudo, K., Murakoshi, T., \& Ohtsuki, T. (2009). Music performance anxiety in skilled pianists: effects of social-evaluative performance situation on subjective, autonomic, and electromyographic reactions. Experimental Brain Research, 199, 117-126. DOI: 10.1007/s00221-009-1979-y

Zaza, C. (1992). Playing-related health problems at a Canadian music school. Medical Problems of Performing Artists, 7, 48-51.

Zaza, C., Charles, C., \& Muszynski, A. (1998). The meaning of playing-related musculoskeletal disorders to classical musicians. Social Science and Medicine, 47, 2013-2023.

Zaza, C., \& Farewell, V. T. (1997). Musicians' playing-related musculoskeletal disorders: an examination of risk factors. American Journal of Industrial Medicine, 32, 292-300.

Zetterberg, C., Backlund, H., Karlsson, J., \& Werner, P. T. (1998). Musculoskeletal problems among male and female music students. Medical Problems of Performing Artists, 13, 160-166. 